\title{
O Consumo Infantojuvenil como Fator de Deturpação das Relações Familiares em Busca de uma Regulamentação Jurídica Adequada
}

\section{Hilda Maria Couto Monte}

Mestre em Direito pela Universidade Federal de Alagoas (Ufal). Especialista em Direito Constitucional pela Ufal. Professora de Direito das Famílias do Centro Universitário Cesmac e Advogada em Maceió/AL. hcoutomonte@ gmail.com

\section{Olga Jubert Gouveia Krell}

Professora-associada de Sociologia do Direito dos Cursos de Graduação e Mestrado da Faculdade de Direito de Alagoas (FDA-Ufal). Doutora em Direito pela Faculdade de Direito do Recife (UFPE). Coordenadora do Núcleo de Pesquisa da FDA-Ufal. Líder do Grupo de Pesquisa Laboratório de Direitos Humanos (CNPq) e membro da Diretoria da Associação Brasileira de Pesquisadores em Sociologia do Direito (ABraSD). olgajgk@uol.com.br

\section{RESUMO}

0 consumo infantojuvenil ganha proporções cada vez maiores na sociedade brasileira, causando a coisificação das relações interpessoais. 0 objetivo deste artigo é identificar, numa perspectiva interdisciplinar, as bases psicológicas, sociais e culturais desse fenômeno, demonstrando os seus efeitos negativos em relação às estruturas familiares no Brasil e a consequente violação de dispositivos constitucionais referentes à proteção da família, bem como da infância e da juventude. Igualmente serão apresentadas a regulamentação concreta da restrição de publicidade que incentiva o consumo infantojuvenil e as decisões jurisprudenciais mais importantes sobre este controle. Por fim, haverá 
uma analise do Projeto de Lei sobre o assunto que tramita no Congresso Nacional. Veremos que 0 problema exige uma atuação enérgica do Legislativo, do Executivo e do Judiciário em defesa dos valores da dignidade humana e da proteção da defesa da família consagrados na Carta de 1988.

Palavras-chave: Consumo. Crianças e adolescentes. Proteção constitucional da família. Projeto de Lei n. 5.921/2001.

\title{
Consumption of children and teenagers as a factor of disturbance in family relationships: in search of appropriate legal regulations
}

\begin{abstract}
Children's and teenager's commercial consumption gains increasing proportions in Brazilian society, causing degradation of interpersonal relationships. This article aims to identify, in an interdisciplinary perspective, the psychological, social and cultural bases of this phenomenon, showing its negative effects in relation to family structures in Brazil and the consequent violation of constitutional rules concerning family and children's protection. Then, will be introduced the concrete rules about restriction of media and publicity that encourage child and juvenile consumption and the court's most important decisions about this control. Finally, there will be a review of the legislative proposal on the matter that is being discussed in the National Congress. We will see that the problem requires an energetic performance from the Legislative, the Executive and the Judiciary in defense of the values of human dignity and family protection protected by the Constitution of 1988.
\end{abstract}

Keywords: Consumption. Children and teenagers. Constitutional protection of the family. Bill $n$. $5.921 / 2001$

Sumário: 1 Introdução. 2 A problematização do consumo nas relações sociais contemporâneas. 3 Violação à dignidade humana mediante reificação das relações interpessoais. 4 Princípios constitucionais de fundamentação das famílias e sua contextualização diante da cultura do consumo. 5 Regulamentação legal contra publicidade abusiva em favor do consumo comercial infanto-juvenil. 6 0 Projeto de Lei n. 5.921/2001 e o seu Substitutivo, de 2008. 7 Conclusão. 8 Referências. 


\section{INTRODUÇÃO}

O amor enquanto experiência humana idiossincrática perpassa pela compreensão e comunhão de interesses altruístas, na ressurreição daquilo que o homem tem de mais belo: sua solidariedade e sua humanidade. É ele o elemento basilar imprescindível das relações familiares, nas quais se encontra a dignidade do próprio homem e a sua constante busca por pretensa felicidade que se constrói, sobretudo, artesanalmente, ao sabor de reflexões da própria psique humana.

O afeto familiar, contudo, como expressão de amor humano, não deve ser entendido como uma constante universal ou mera manifestação neurofisiológica; antes, este afeto é produto do contexto sociocultural histórico em que as pessoas vivem (COSTA, S., 2005, p. 114). Neste sentido, todas as formas de amor inserem-se no psiquismo humano cuja constituição, segundo Freud, é determinada, antes de tudo, pelos fatores sociais (FUKS, 2007, p. 12).

Ao mesmo tempo, merece registro a assertiva reflexiva de Bauman (2004), segundo a qual a "modernidade líquida" faz-se presente na contemporaneidade e cria um ambiente em que as relações humanas se tornam mais "flexíveis" e cujas consequências respingam na situação atual de insegurança, coisificação do homem e violação da dignidade humana.

Na sociedade líquida, o desejo é algo intrinsecamente ligado ao consumo. Tal visão é imposta pela mídia e outros meios que o mercado utiliza para conduzir os indivíduos a desejar sem fronteiras, levando-os a alterar as próprias relações pessoais. Com efeito, a cultura consumista e perdulária, distante de valores que constituem a base de sustentação dos direitos e garantias fundamentais, termina por incrementar o fenômeno da reificação, que viola a dignidade da pessoa humana, alterando suas perspectivas solidárias de convívio na sociedade e minando, por conseguinte, suas relações familiares. 
Nesse aspecto, a transformação do amor em mero desejo de caráter consumista fragiliza os laços familiares, criando um ambiente instável. Pretende-se demonstrar, a partir de uma necessária contextualização histórica e social, que essa perspectiva de liquidez das sociedades modernas, aliada à distorcida visão sobre consumo, encontra-se diametralmente oposta aos paradigmas principiológicos de caráter constitucional do Direito das Famílias dispostos na Constituição Federal de 1988. Trata-se de uma análise sobre o atual estágio da arte e do consumo exacerbado, presente nas relações sociais familiares.

\section{A PROBLEMATIZAÇÃO DO CONSUMO NAS RELAÇÕES SOCIAIS CONTEMPORÂNEAS}

A origem etimológica da palavra consumir provém do latim consumere, que significa usar, esgotar, destruir - numa perspectiva de esgotamento não apenas de bens materiais, mas, inclusive, física e emocionalmente (CAMPBELL; BARBOSA, 2013, p. 21). Nesse aspecto, consomem-se bens, pessoas e relações familiares intersubjetivas, que são resumidas à instrumentalização para o alcance de determinados fins.

Consumo define-se nessa ótica como "algo entregue à desmesura e à contingência individual das necessidades” (BAUDRILLARD, 2011, p. 95). Segundo Slater, em sua obra Cultura do consumo e modernidade, há uma interligação entre sociedade e cultura do consumo com a modernidade; para o sociólogo, a cultura do consumidor é uma cultura do consumo e uma forma dominante de reprodução social, ainda que não seja a única no Ocidente, firmada ante a modernidade; essa cultura associa-se a valores, práticas e instituições tais como escolha, individualismo e relações de mercado (SLATER, 2001, p. 30 et seq.).

O referido autor aduz que a cultura do consumo está ligada à modernidade, procurando defini-la mediante o que ele denomina de indicadores sociológicos, dentre eles o fato de o consumo ter se tornado na modernidade o foco 
central da vida das pessoas, o que permite uma visão negativa da sociedade contemporânea como sendo uma sociedade materialista, na qual o valor social das pessoas é determinado pelo que elas têm e não pelo que são.

Featherstone (1995, p. 10 et seq.) entende que a utilização da expressão "cultura do consumo" implica destacar que o mundo das mercadorias juntamente com seus princípios estruturais são relevantes para o entendimento da sociedade contemporânea. Esse autor também considera a cultura do consumidor como uma cultura da pós-modernidade, atrelando sempre a expansão do capitalismo atual com a imprescindibilidade da criação de novos mercados e de "educação" para o consumo das pessoas, aperfeiçoando e criando novos mecanismos de sedução e manipulação ideológicas pelo marketing e pela propaganda.

Exatamente neste ponto emergem os problemas sociais diante do consumismo perdulário, proveniente desta nova e devastadora perspectiva sobre a vida e a convivência, bem como sobre a identidade das pessoas. Em perspectivas similares, para Bourdieu (2007), as mercadorias são usadas para comunicar e distinguir socialmente práticas e estratégias de consumo de variados segmentos da sociedade, influenciando nos hábitos, identidades e diferenciações.

Bauman (2007, p. 37) estabelece distinções relevantes entre a definição de consumo e consumismo, aduzindo que

o consumo é algo banal, até mesmo trivial, é uma atividade que fazemos todos os dias (...). Se reduzido à forma arquetípica do ciclo metabólico de ingestão, digestão e excreção, o consumo é uma condição, e um aspecto, permanente e irremovível, sem limites temporais ou históricos; um elemento inseparável da convivência biológica que nós humanos compartilhamos com todos os outros organismos vivos. Visto dessa maneira, o fenômeno do consumo tem raízes tão antigas quanto os seres vivos (...).

Já no que concerne ao consumismo, o autor assim o conceitua: 
Consumismo é um tipo de arranjo social resultante da reciclagem de vontades, desejos, anseios humanos rotineiros, permanente e, por assim dizer, "neutros quanto ao regime", transformando-os na principal força propulsora e operativa da sociedade, uma força que coordena a reprodução sistêmica, a integração e a estratificação sociais, além da formação de indivíduos humanos, desempenhando ao mesmo tempo um papel importante nos processos de auto-identificação individual e de grupo, assim como na seleção e execução de políticas de vida individuais (BAUMAN, 2007, p. 41).

Contextualizando o consumo nas relações afetivas, é possível afirmar que o amor da contemporaneidade líquida é o que Bauman chamou de "amor de bolso": aquele que não tolera os aborrecimentos e conflitos normais da convivência em comum. Nesse aspecto, o autor realiza uma crítica às atuais relações humanas, estabelecendo a distinção entre amor e desejo à relação de posse, satisfação, perpetuação, e ressalta o equívoco de confundir amor com situações episódicas de satisfação sexual e relacional entre as pessoas envolvidas. Nessa perspectiva, a cultura consumista termina por vincular amor a desejo; o consumo estaria atrelado ao desejo que, por sua vez, revela o comportamento social atual. Significa dizer que a forma como as pessoas se relacionam hoje é a forma como se consomem os objetos, evidenciando o equívoco de confundir desejo e amor.

O autor destaca que na contramão das relações consumistas o amor está ligado à solidariedade, ao sentimento de pertença e identidade do outro reconhecido em si. Assim, "enquanto a realização do desejo coincide com a aniquilação de seu objeto, o amor cresce com a aquisição deste e se realiza na sua durabilidade. Se o desejo se autodestrói, o amor se autoperpetua” (BAUMAN, 2004, p. 24). Com efeito, a lógica do consumo impede esse olhar de continuidade.

Não há base para a efetivação da dignidade da pessoa humana sem que haja uma alteração dos paradigmas atuais, isto é, dos não valores da sociedade consumista que engrenam os interesses de grupos mercantis específicos. 
Por isso, são imprescindíveis a formatação e a instituição de políticas públicas de educação para o consumo responsável, a indicação de valores solidários, a proteção à família e aos vulneráveis das relações familiares. O retorno ao paradigma lastreado pelo princípio da dignidade humana somente poderá ser alcançado com a ajuda do Direito como meio coercitivo, mediante leis protetivas, fiscalizatórias e incentivadoras do consumo responsável e consciente, políticas educacionais do Estado voltadas a este objetivo e penas mais severas a empresas que quebrarem a proteção da dignidade humana ou que apresentem pessoas como coisas.

As práticas educativas devem direcionar-se para propostas pedagógicas focadas na conscientização, mudança de comportamentos e atitudes, além do desenvolvimento de competências, capacitando a avaliação e participação dos educandos; isso é um desafio à sociedade da cultura consumista, pois implica uma reformulação do pensamento (FLORIANI, 2003, p. 116). Ao mesmo tempo, parece ser o único caminho para que os atuais padrões de comportamento sejam alterados no sentido de frear a alienação e o culto ao consumo.

Cabe sublinhar, ao mesmo tempo, que a globalização foi concebida como uma tentativa de homogeneização do mundo mediante um mercado global. Essa ideia impressionou a todos, mas nas entranhas mostrou-se como uma "fábrica de perversidades", em que fome, desemprego, má qualidade de vida e desabrigados multiplicam-se em todos os continentes. Para Santos (2001, p. 19), a globalização contribui para a fragilidade de valores até então unificadores das pessoas, em suas relações interpessoais, sociais e familiares, retirando delas suas bases de solidariedade estruturadoras, além do sentimento de pertença e identificação. A globalização em seu aspecto pervertido e caricato retira dos indivíduos seus "territórios de pertenças”, o que envolve uma afronta à liberdade e ao princípio da dignidade humana, à custa da alienação humana e da usurpação de sua identidade. 
A globalização é o clímax de um processo de internacionalização do capitalismo mundial em que o consumo atrofiado ou hiperconsumismo é estimulado a ponto de se tornar a razão de ser dos indivíduos. O dissipar do ideal de solidariedade tem sua origem neste contexto, sob o aspecto econômico, impondo às pessoas a sensação de desamparo e solidão que assola o mundo atual (BAUMAN, 2004, p. 172). No mundo globalizado, os valores, tradições, crenças, bem como os padrões comportamentais das relações familiares quedaram relativizados. Dessa maneira, na modernidade líquida, as instituições e os códigos sociais e morais não conseguem estabelecer mais agrupamentos referenciais sólidos que configurem modelos direcionadores da existência humana.

O ponto negativo disso, no entendimento de Giddens (2006, p. 56), é sentido quando há um crescente incremento das compulsões, como drogas e alcoolismo no meio familiar, podendo o ser humano se viciar em trabalho, exercícios, comida, sexo ou até em amor, uma vez que essas atividades "estão muito menos estruturadas pela tradição e o costume do que eram outrora”. O ponto positivo desse diagnóstico é a possibilidade de um estilo de vida mais autônomo e aberto, visto que toda a responsabilidade pela vida das pessoas reside nelas mesmas. Aqueles que viviam nos séculos anteriores jamais tiveram tal experiência de liberdade. $\mathrm{O}$ declínio da tradição, no entanto, e a quase livre-escolha do estilo de vida atingiram fortemente a própria individualidade do ser humano, o que faz com que "o senso de identidade tem que ser criado e recriado de forma mais ativa que antes” (GIDDENS, 2006, p. 57). Diante dessa abordagem sociológica, constata-se a banalização dos relacionamentos humanos estimulados pelo consumo desmedido. Merece registro também a problematização da perspectiva teórica sobre a reificação das relações humanas e sua agressão à dignidade da pessoa humana, como se verá a seguir. 


\section{VIOLAÇÃO À DIGNIDADE HUMANA MEDIANTE A REIFICAÇÃO DAS RELAÇÕES INTERPESSOAIS}

Encarar o amor é algo difícil e demanda tempo, dedicação e concessões que nem sempre as pessoas estão dispostas a fazer; assim, o ser humano rejeita sua própria incompletude e procura superar essa solidão mediante a aquisição de mercadorias. São os membros da sociedade de consumo eles próprios mercadorias, entretanto, e é a qualidade de ser uma mercadoria de consumo que os torna membros autênticos dessa sociedade (BAUMAN, 2007). Nesse contexto, "a alienação se entende como privação da capacidade de ser sujeito, pela reificação das relações sociais; entende-se como desencantamento que esvazia a experiência social do seu sentido, através da racionalidade instrumental" (WAUTIER, 2003, p. 184).

A coisificação humana é um tema que emerge dessa relação do homem e sua vivência no ritmo dos objetos. As pessoas que convivem com objetos terminam gerando em seus comportamentos e padrões semelhantes à forma como lidam com as coisas. Isto é o que os sociólogos chamam de "reificação das relações humanas”. A onipresença das mercadorias na vida humana adquiriu significados complexos a ponto de não consumirmos mais bens, mas sim signos representativos de prestígio (SENNETT, 2012).

Para Debord (2011, p. 16 et seq.), vive-se numa "sociedade espetaculosa”, uma vez que, numa visão geral, o espetáculo é nada mais do que o modelo dominante de vida da sociedade moderna, o que também reflete a imagem da economia atual. A realidade individual passa a ser social, dependente de e moldada por forças sociais, com o espetáculo como a "realização técnica do exílio, para além das potencialidades do homem; a cisão consumada no interior do homem”. Neste contexto, as mercadorias transcenderam sua condição fenomênica e fundiram-se com a linguagem, adquirindo um sentido simbólico em que as pessoas buscam nos objetos seus significados; elas são atrativas na medida em que geram símbolos 
de poder e status. Com efeito, as pessoas procuram no mercado produtos que tenham o poder de agregar valor e status a sua personalidade. As pessoas devem, sob pena de exclusão, adequar-se a uma existência na qual predomina a visão do "efêmero", o "reino da frivolidade" e as "novidades e fantasias" (LIPOVETSKY, 2009). O efeito colateral dessa forma de viver é a perda da autonomia do indivíduo, substrato material inicial de sua dignidade humana. Assim, "o aparato produtivo e as mercadorias se impõem ao sistema social como um todo”, o que impede os indivíduos de serem sujeitos autônomos e molda a sua consciência através das formas de domínio social” (SOUZA, 2014).

A reificação foi entendida como um fenômeno de identificação do homem como objeto, comumente conhecida também como "coisificação" humana, e que, para a maior parte dos sociólogos, tem ocasionado as anomias presentes em todas as relações sociais, entre elas as familiares, bem como agressão ao princípio maior da dignidade da pessoa humana. ${ }^{1}$

Essa reificação das relações afetivas e sociais faz surgir o que Bauman (2004) trata como "relações de bolso"; sobre elas destaca que, caso se note que algo que não se negociou e para o qual não se foi atendido, "é hora de seguir adiante", uma vez que a intenção do "viver juntos" revelou-se obscura, efêmera e passageira.

Noutro giro, contextualiza-se a questão da reificação das relações familiares a partir de uma crítica denunciativa contra a omissão do Estado brasileiro na fiscalização e no combate aos casos que afrontam a família e sua função na sociedade, a exemplo do aumento da pedofilia, da erotização e mesmo da tolerância à prostituição infantojuvenil, que se fazem presentes nos noticiários brasileiros. Servem como exemplos os bailes funk, que são regados a álcool,

${ }^{1}$ O termo "reificação" foi utilizado pela primeira vez pelo sociólogo marxista Gyorge Lukács, em sua obra História e Consciência de Classe e voltava-se apenas às relações de trabalho e de classe. A temática ganhou contornos mais abrangentes e interdisciplinares ao abordar o fenômeno em outras áreas do convívio social, dentre elas a família. 
drogas e sexo, com crianças erotizadas, cujos corpos são meros objetos de consumo sexual. Além disso, cresce vertiginosamente o número de episódios de pedofilia e erotização das crianças e adolescentes via celular e Internet no país. As crianças, assim como os adultos, são vistos como coisas, objetos de desejo e de consumo; são os tentáculos da visão do homo sexualis sobre a infância, que não impõem mais limites, nem mesmo dentro das famílias. ${ }^{2}$

Trata-se de uma reação em cadeia, fruto da relação simbiótica entre consumismo, erotização e reificação humana, temas que conduzem a problemas familiares e à agressão aos direitos protetivos de crianças e adolescentes. A erotização e a reificação da infância são decorrentes também da influência publicitária e do marketing infantojuvenil. Trata-se de uma contínua violação aos princípios constitucionais insculpidos no artigo 227 $\mathrm{CF}$, tais como a dignidade da pessoa humana, proteção integral da criança e do adolescente e o melhor interesse do menor.

Como exemplo da reificação das relações humanas promovidas por membros da própria família pode-se citar um programa de televisão denominado "Pequenas Misses", no qual vislumbra-se a erotização de crianças e o culto ao corpo, com pais que utilizam os corpos de seus filhos (devidamente erotizados) a fim de ganhar prêmios e status social. Numa análise mais profunda, constata-se a usurpação da infância e adolescência pelo ideal da cultura consumista, o que afronta o princípio constitucional da proteção integral do menor e sua infância. Em suma, as questões familiares, ao invés de serem enfrentadas entre seus membros, levando-se em consideração os ideais constitucionais de solidariedade familiar, afetividade e paternidade responsável, são abordadas

${ }^{2}$ Conforme dados de 2012 e 2013, fornecidos pela Polícia Federal e pela ONG Safernet Brasil, entidade que monitora crimes e violações contra direitos humanos na internet, das 244.147 denúncias anônimas recebidas, 80.195 , ou seja, 32,84\% são inerentes à pornografia infantil na $w e b$, que envolve 24.993 páginas diferentes, hospedadas em 8.589 servidores distintos e atribuídos a 64 países em 5 continentes. Ao mesmo tempo, o número de prisões em flagrante por este crime duplicou no referido período. Disponível em: $<$ www.crimespelainternet.com.br/numero-de-prisoes-por-pornografia-infantil-na-web-cresce-127/>. 
superficialmente como capítulos de novelas, filmes e seriados. Enquanto isso, as Varas de Família do Judiciário, num esforço hercúleo, tentam remendar o que sobrou de lares destroçados, muitas vezes pela influência da ideologia do entretenimento (COSTA, J., 2005).

Sem dúvida, a sociedade não se configura como um ente abstrato e dissociado da pessoa humana. Na contemporaneidade, porém, conviver em sociedade implica, para alguns, dirimir ou mesmo esquecer as próprias experiências pessoais, sentimentos, ideias e ações sociais, desembocando no abandono de suas convicções éticas. Esses aspectos da realidade social favorecem o acolhimento de um tipo de sociedade líquida e consumista, que se conecta superficialmente por meio de redes de relações humanas incapazes de traçar um pensamento reflexivo de relativa autenticidade. Nesse sentido, o subsistema social compromete a observância dos princípios constitucionais de Direito de Família, como se verá a seguir.

\section{PRINCÍPIOS CONSTITUCIONAIS DE FUNDAMENTAÇÃO DAS FAMÍLIAS E SUA CONTEXTUALIZAÇÃO DIANTE DA CULTURA DO CONSUMO}

Após a Segunda Guerra Mundial, foram solidificados os valores fundamentais da pessoa humana no texto das Constituições. No Brasil, a dignidade da pessoa humana foi consagrada na Constituição de 1988, em seu artigo $1^{\circ}$, inciso III. Ao se tornar princípio constitucional, a dignidade humana trouxe toda a carga axiológica que dela decorre, materializada na liberdade, igualdade, fraternidade, incolumidade física e psíquica, firmando-se como núcleo intocável e contaminante de todo ordenamento jurídico. Kant (1986, p. 77), referindo-se à dignidade humana, destaca que 
no reino dos fins tudo tem ou um preço ou uma dignidade. Quando uma coisa tem um preço, pode se pôr em vez dela qualquer outra equivalente; mas quando uma coisa está acima de todo o preço, e, portanto, não permite equivalente, então tem ela dignidade.

Dessa maneira, agride o princípio da dignidade humana toda forma de agir que coisifique o ser humano, que o trate como um objeto, uma coisa em disponibilidade. Essa dignidade possui um caráter intersubjetivo e relacional, impondo um dever de respeitabilidade no meio da comunidade de seres humanos (SARLET, 2010, p. 37). Nesse contexto, a família constitui um ambiente comunitário por excelência na persecução de uma existência digna e de comunhão entre as pessoas, calcada na funcionalidade de desenvolvimento da dignidade das pessoas humanas que a compõem (LÔBO, 2008, p. 37 et seq.). A importância da família contextualizada no princípio da dignidade humana acopla deveres imprescindíveis direcionados à persecução de sua função na sociedade. Tal desiderato acha-se expressamente disposto no artigo $227 \mathrm{CF}^{3}$

Trata-se de um direito oponível a todos: Estado, sociedade e mesmo estranhos, mas, principalmente, a todos os que compõem as entidades familiares em geral. Os paradigmas constitucionais da dignidade humana contaminam toda a legislação infraconstitucional familiar. ${ }^{4}$ Assim, qualquer maneira de se relacionar de forma reificadora resultará, tanto no meio social quanto no familiar, em agressão a este princípio jurídico básico.

\footnotetext{
${ }^{3}$ Art. 227. É dever da família, da sociedade e do Estado assegurar à criança, ao adolescente e ao jovem, com absoluta prioridade, o direito à vida, à saúde, à alimentação, à educação, ao lazer, à profissionalização, à cultura, à dignidade, ao respeito, à liberdade e à convivência familiar e comunitária, além de colocá-los a salvo de toda forma de negligência, discriminação, exploração, violência, crueldade e opressão (Redação dada pela EC $\mathrm{n}^{0} 65$, de 2010).

${ }^{4}$ A exemplo de sua exaltação nos artigos $3^{\circ}, 4^{\circ}, 15$ e 18 do Estatuto da Criança e do Adolescente - ECA (Lei 8.069/1990) bem como no Código Civil de 2002 e nas demais legislações infraconstitucionais.
} 
Apesar da consagração deste princípio, testemunha-se, já no século 20, o despertar de uma sociedade que adota a "cultura do consumismo". Bauman (2007, p. 41), enfatiza que

o "consumismo" é um tipo de arranjo social resultante da reciclagem de vontades, desejos e anseios humanos rotineiros, permanentes e, por assim dizer, "neutros quanto ao regime", transformando-os na principal força propulsora e operativa da sociedade, uma força que coordena a reprodução sistêmica, a integração e a estratificação sociais, além da formação de indivíduos humanos, desempenhando ao mesmo tempo um papel importante nos processos de auto-identificação individual e de grupo, assim como na seleção e execução de políticas de vidas individuais.

Nesse aspecto, a cultura consumista ajudou a erigir novos padrões, modos comportamentais, costumes e hábitos, além de outros símbolos culturais de identidade que influenciaram toda uma geração de crianças, jovens e adultos. A partir da generalização da produção em massa na década de 60 do século 20, os valores individuais como liberdade, independência, autoafirmação, singularidade, felicidade individual, saúde, satisfação e prazer da cultura juvenil foram cooptados pelas grandes indústrias. A partir daí se encorajou, se promoveu e se reforçou um estilo de vida mais individualista e mais consumista (SOUZA, 2012).

Desde o início do século 21, as pessoas em muitas partes do mundo tiveram acesso crescente a uma multiplicidade de bens materiais e culturais, os quais "eram frequentemente vislumbrados não só como portadores de maior conforto e comodidade, mais ainda de uma vida melhor" (PAES, 1995, p. 13).

Este consumismo tem em seu entorno o individualismo e a manipulação das ações pessoais, em detrimento dos sentimentos gregários, solidários. Na perspectiva da prática social, o acolhimento da solidariedade e o afastamento do consumo desmedido são o desafio do mundo globali- 
zado, caracterizado por fissuras valorativas e egocentrismo. Neste ponto, confirmam-se as palavras de Fromm (2006, p. 12), para quem "o homem - de todas as eras e culturas - vê-se sempre diante do mesmo problema: como superar o estado de separação, como alcançar a união, como transcender sua vida individual e encontrar a reconciliação”.

Não se pode falar em superação humana e transcendência da vida individual exercida dignamente sem a solidariedade, visto que nela consiste a reconciliação do homem consigo mesmo e com os que o cercam. Outro princípio importante no Direito de Família é o da afetividade, que também é constantemente violado devido à prática do consumismo. Hoje existe um déficit emocional nas relações afetivas entre muitos pais e filhos, ocasionado pela ausência e pelas omissões paterno-filiais, lacunas que a cultura consumista aproveita para ocupar e para substituir a lógica do afeto pela irracionalidade do possuir desmedido. Com efeito, o princípio da afetividade lastreia o Direito de Família no que se refere à estabilidade das relações socioafetivas bem como na comunhão de vidas. ${ }^{5}$

Embora implícito na Constituição, tal princípio revela a dignidade da pessoa humana e a solidariedade familiar, fazendo nascer no ser humano o intuito constitutivo de formação familiar e agregação solidária. Tepedino (1997, p. 56) enfatiza a importância deste princípio, que se expressa na função da família de desenvolver a personalidade de seus membros. Colabora com a afetividade, complementando-a, o princípio da convivência familiar, que é “a relação afetiva diuturna e duradoura entretecida pelas pessoas que compõem o grupo familiar, em virtude de laços de paren-

${ }^{5}$ Largamente utilizado pela doutrina e jurisprudência, muitas vezes é confundido com o afeto, este último um mero elemento anímico e psíquico. A afetividade implica responsabilidades familiares e uma vida familiar voltada para a construção sólida das relações entre os seus membros, das quais emergirão a solidariedade e o sentido de coletividade e bem-estar familiar. 
tesco ou não, no ambiente comum”, isto é, “o ninho no qual as pessoas se sentem recíproca e solidariamente acolhidas e protegidas, especialmente as crianças” (LÔBO, 2008, p. 52).

A grande questão atual é justamente repensar como esse princípio está sendo instituído na prática, uma vez que há pouco tempo e espaço para a convivência familiar, que foi reduzida pela evolução tecnológica da comunicação. Não se vive mais na companhia humana numa relação interacional direta, mas há um convívio demarcado por uma comunicação pautada pela utilização preponderante de objetos. Assim, o conjunto das relações sociais já não se dá tanto com seus semelhantes, mas com as coisas. Os homens tornaram-se funcionais na proporção em que começaram a viver no ritmo dos objetos e de acordo com suas sucessões constantes, rápidas e permanentes (BAUDRILLARD, 2011). Não se vive apenas no ritmo das coisas, mas atribui-se ao próprio ser humano a condição de objeto.

Para Bauman (2004, p. 59), na modernidade líquida o filho tornou-se um “objeto de consumo emocional”; isso atesta que as estruturas familiares estão fragilizadas e suas expectativas de duração, cada vez mais curtas; não há a perenização destas relações. Segundo o autor, houve uma verdadeira monetarização da paternidade: como nos objetos de consumo, a satisfação esperada tende a ser medida pelo (alto) custo que os filhos causam aos pais.

Essa percepção social dissocia-se totalmente da concepção jurídica da convivência familiar formadora de vínculos sólidos entre os membros das famílias, o que revela a incapacidade do Estado, que não consegue refletir a legitimidade de seus fins existenciais e jurídicos para impor a sua concepção legal diante de uma cultura da puerilidade e flexibilidade. Nesse prisma, surge o princípio constitucional do melhor interesse da criança, 
que não representa uma mera recomendação de caráter ético, mas um efetivo norte jurídico referente às relações entre crianças e adolescentes perante os seus pais (LÔBO, 2008, p. 55).

É inegável a necessidade de proteção dos menores e da família, tendo como lastro os princípios constitucionais de Direito de Família que são vilipendiados pela prática social abusiva. Entre eles, o princípio constitucional da função social da família, que cumpre um papel não apenas na sociedade, mas na vida das pessoas que a compõem: núcleo acolhedor do respeito, solidariedade, transmissão de valores humanitários e proteção, que são invioláveis, pois estão intrinsecamente ligados à dignidade da pessoa humana e sua construção social.

É na família que o indivíduo desenvolverá sua autonomia, que é o "primeiro requisito para o livre e pleno desenvolvimento da personalidade humana”, ou seja, a pessoa "ser dotada de discernimento e vontade própria” (MORAIS, 2013, p. 593). Qualquer padrão que fuja a essas premissas invade a autonomia da vontade e desestabiliza as relações familiares.

Na contemporaneidade há uma inversão de valores, os quais tinham como lastro a família, a crença em ideais políticos libertários e de cidadania ativa, dos quais os grupos sociais lançavam mão (COSTA, 2012). Em sua função, a família desponta como um instrumento à disposição da sociedade para a obtenção da felicidade, que apenas pode ser palpável na relação com o outro. Nesse sentido, "a principal função da família é a sua característica de meio para a realização de nossos anseios e pretensões”; ela não é mais um fim em si mesma, senão o meio social para a busca de nossa felicidade na relação com o outro (GAGLIANO; PAMPLONA FILHO, 2011, p. 98). A aplicação das normas constitucionais e infraconstitucionais do Direito de Família exige uma sintonia com o prisma garantista da Carta de 1988 e também com a solidariedade que se impõe, assegurando-se a funcionalidade dos institutos do Direito de Família (FARIAS; ROSENVALD, 2015). Sendo a família um espaço de integração social, deve-se afastar dela a 
compreensão hedonista e individualista, que são características da sociedade consumista, e com isso otimizar um ambiente de segurança e de boa convivência. A responsabilidade dos pais em relação aos filhos deve estar respaldada na criação de um ambiente familiar sadio e propício à construção da autonomia da vontade da criança e do adolescente.

O consumismo tem se mostrado um fator desestabilizador das funções familiares e dos demais princípios constitucionais relacionados à família. Atualmente, a paternidade responsável, princípio prescrito no artigo 226 , $\S 7^{\circ}$, tem sido negligenciada, uma vez que a cultura do consumo dificulta a construção de relações paterno-filiais sólidas. Com isso, aumenta a importância da educação dada pelos pais aos filhos, os quais não absorvem facilmente o código de ética e as regras de comportamento impostos pelos pais, sendo preciso "ensinar, instruir, dar exemplos, usar recompensas e castigos, e assim por diante” (MORAIS, 2013, p. 595).

\section{REGULAMENTAÇÃO LEGAL CONTRA PUBLICIDADE ABUSIVA EM FAVOR DO CONSUMO INFANTOJUVENIL}

É notório que crianças e adolescentes podem ser manipulados com mais facilidade do que adultos, uma vez que ainda se encontram em desenvolvimento e em constante assimilação de valores. Por isso, a condução deles a serem os futuros agentes integrados no esquema da cultura consumista é mais acirrada e começa logo cedo. Enquanto não atingem a idade da independência econômica, o marketing lança mão deles como instrumento para atingir os pais, influenciando o consumo adulto e, ao mesmo tempo, estimulando uma convivência entre pais e filhos marcada pela reificação. Hoje em dia as horas de ócio de boa parte dos jovens estão preenchidas pela televisão e pela Internet, que chegaram a substi- 
tuir boa parte das "sociabilidades não estruturadas"; com isso, aumentou bastante o seu interesse em relação a mercadorias e suas relações de consumo (SCHOR, 2009, p. 9).

A publicidade, hoje, é a principal fonte de informação e estímulo ao consumismo infantil. As estratégias publicitárias das empresas tentam impor às crianças um processo de aprendizagem e educação para o consumo, o que se manifesta pela intensidade e pelo conteúdo do discurso de marketing; este é mais invasivo e importuno do que nunca. Estudos revelam que nos últimos anos as crianças e adolescentes no Brasil adquirem hábitos de consumo de forma mais precoce devido às alterações ocorridas na dinâmica familiar das últimas décadas e ao impacto da tecnologia no ambiente infantojuvenil (VENTURA, 2010, p. 6).

Além de a criança ser a destinatária de objetos de consumo, ela também é instrumento intermediário do consumo de seus pais; os marqueteiros criam conexões diretas com as crianças, utilizando-as para convencer os pais a gastar dinheiro. Tal fato faz nascer o chamado "fator amolação", que é uma forma de usar a criança para levar seus pais a adquirirem certos produtos e tem gerado inúmeros aborrecimentos, minando a harmonia relacional entre pais e filhos. A negativa aos apelos dos filhos termina por colocar os pais na condição de “inimigos".

A vulnerabilidade da criança e do adolescente exige um tratamento especial por parte do legislador, lastreado no princípio da isonomia, no sentido de tratar de forma diferenciada pessoas que se encontram mais propensas a ser persuadidas se comparadas às demais. Os menores são bem mais vulneráveis que os demais consumidores, posto que podem ser facilmente induzidos ao erro e manipulados pelos interesses dos fornecedores de produtos e suas campanhas de marketing. Assim, as propagandas agraciam as emoções, não o intelecto, e atingem as crianças de uma maneira mais incisiva e profunda do que os adultos. 
O Código de Autorregulamentação Publicitária, de 1978, editado por Resolução do Conselho de Autorregulação Publicitária (Conar), ${ }^{6}$ não tem força de lei, mas constitui um código de ética profissional que também estabelece normas referentes à publicidade infantil. Segundo o seu artigo 37, anúncios dirigidos a crianças e jovens devem dar "atenção especial às características psicológicas da audiência-alvo", respeitar "a ingenuidade e a credulidade, a inexperiência e o sentimento de lealdade dos menores" e não os ofender moralmente, não sugerir uma "inferioridade do menor, caso este não consuma o produto oferecido”; além disso, não é permitido que o anúncio estimule o menor a "constranger seus responsáveis ou importunar terceiros ou o arraste a uma posição socialmente condenável”; por fim, a norma deixa claro que "o uso de menores em anúncios obedecerá sempre a cuidados especiais que evitem distorções psicológicas nos modelos e impeçam a promoção de comportamentos socialmente condenáveis” e que “qualquer situação publicitária que envolva a presença de menores deve ter a segurança como primeira preocupação e as boas maneiras como segunda preocupação”.

Infelizmente, essas regras éticas dificilmente são consideradas pelos publicitários, que lançam mão de todos os mecanismos e técnicas possíveis para acirrar os desejos e sedimentar padrões de comportamento consumistas, alimentando o imaginário das pessoas. As crianças, quando não conseguem o objeto desejado, não apenas perturbarão os pais, mas também a si próprias, pois o consumo está muito associado à ideia de felicidade. Numa sociedade caracterizada por uma desigualdade social enorme, a programação da televisão que chega às casas das famílias pobres cria problemas psicológicos tanto para a criança quanto para a família (SUCUPIRA, 2006).

${ }^{6}$ Disponível em: <www.mprs.mp.br/infancia/legislacao/id2156.htm>. Acesso em: 21 set. 2015. 
O artigo 220, $\S 3^{\circ}$, II, da CF estabelece a competência federal para firmar os mecanismos legais de garantia à pessoa humana e à família, referentes à defesa destes em razão dos "programas ou programação de rádio e televisão" e da publicidade e de outros produtos com nocividade. É deste artigo que surge a autorização constitucional a lastrear a implementação de normas ordinárias tendentes ao controle legal da atividade publicitária comercial, para que não se verifiquem abusos em detrimento dos direitos do consumidor e agressões aos núcleos familiares e à dignidade humana (NERY JÚNIOR, 1995).

No Brasil, já existem normas jurídicas para o controle publicitário; entretanto trata-se de uma matéria altamente complexa e em permanente mutação. A legislação atual peca por não abordar de forma mais criteriosa a tutela jurídica dos menores de idade no contexto da publicidade infantojuvenil. Para a caracterização legal da índole abusiva não é preciso uma lesão concreta, mas tão somente a existência de um perigo abstrato de um dano potencial do anúncio que revela elementos prejudiciais futuros, razão pelo qual não deverá ser divulgado. Assim, o CDC dispõe:

Art. 37. É proibida toda publicidade enganosa ou abusiva. (...)

$\S 2^{\mathrm{o}} \mathrm{E}$ abusiva, dentre outras a publicidade discriminatória de qualquer natureza, a que incite à violência, explore o medo ou a superstição, se aproveite da deficiência de julgamento e experiência da criança, desrespeita valores ambientais, ou que seja capaz de induzir o consumidor a se comportar de forma prejudicial ou perigosa à sua saúde ou segurança (Grifo nosso). ${ }^{?}$

${ }^{7} \mathrm{Na}$ base desta norma o STJ considerou abusiva a campanha publicitária que, em emissoras de rádio cujo público-alvo é o jovem, simula diálogo havido entre pai e filha adolescente, por meio do qual aquele permite que esta mantenha relações sexuais no interior da residência familiar, causando distúrbios aos vizinhos, desde que não tenha que lhe emprestar o seu automóvel (STJ - AC 249201/SC, 2007.024920-1, Quinta Câmara de Direito Civil, Rel. Henry Petry Junior, j. 31.5.2011). 
Essa regra proíbe que se aproveite a deficiência de julgamento e a experiência da criança nas publicidades a ela dirigidas. O Código ainda determina no seu artigo 36, caput, que "a publicidade deve ser veiculada de tal forma que o consumidor, fácil e imediatamente, a identifique como tal”. Assim, a criança poderá verificar imediatamente quando há publicidade.

Além do controle da publicidade diante da proteção integral da criança, o CDC, no artigo 39, IV, firma como prática abusiva no mercado de consumo "prevalecer-se da fraqueza ou ignorância do consumidor, tendo em vista sua idade, saúde, conhecimento ou condição social, para impingir-lhe seus produtos ou serviços”. A legislação e a doutrina denominam "hipossuficientes" os consumidores que integram certas categorias, tais como idosos, crianças, índios, doentes, rurícolas, moradores de periferia e analfabetos, que normalmente estão em situação de vulnerabilidade.

Sendo crianças e adolescentes considerados hipossuficientes, qualquer publicidade que se aproveita de sua credulidade, inexperiência, ingenuidade ou condição de desenvolvimento físico-psíquico é vedada, haja vista ser abusiva por violar os princípios da confiança, lealdade e harmonia que permeiam as relações de consumo. Com isso, há violação da própria liberdade do consumidor, pois as suas escolhas são limitadas e manipuladas pelas estratégias de marketing abusivas, agressivas e intencionais. Por meio delas, a escolha por consumir determinado produto ou serviço não é o resultado de autodeterminação, senão causada por constrangimentos externos de fonte econômica e social (SARMENTO, 2008, p. 143).

O Estatuto da Criança e do Adolescente (ECA - Lei 8.069/90) define a criança como sendo a pessoa até 12 anos de idade incompletos (artigo $2^{\circ}$ ). $\mathrm{O}$ artigo $76^{8}$ serve como elemento norteador na prevenção

\footnotetext{
8 “Art. 76. As emissoras de rádio e televisão somente exibirão, no horário recomendado para o público infanto-juvenil, programas com finalidades educativas, artísticas, culturais e informativas. Parágrafo único. Nenhum espetáculo será apresentado ou anunciado sem
} 
dos efeitos maléficos dos programas de TV e propagandas veiculadas em outros meios comunicativos, que ensejam a exaltação de condutas antiéticas como se fossem corretas, apenas com o intuito de incentivar o consumo. Essa norma está na linha do artigo 221, VI, da CF, segundo o qual a programação das emissoras de rádio e televisão deve atender ao princípio do "respeito aos valores éticos e sociais da pessoa e da família".

Quando a Constituição menciona a família, ela pretende proteger a sua existência e formação, no sentido de revelar suas funções no meio social. $\mathrm{O}$ instituto mediante o qual a família cumpre sua função social e permite a perpetuação da unidade familiar é o poder familiar. O Código Civil brasileiro (Lei 10.406/02) delega aos pais o dever de criar e educar seus filhos (artigo 1.634). A educação não implica apenas colocar numa escola, mas transmitir conhecimentos domésticos e culturais, valores intrínsecos da família, estabelecer um senso de historicidade e agregação ao meio em que vive o menor, além de direcioná-lo para caminhos sadios e de projeções benéficas para toda a sua vida. A publicidade voltada para o consumismo infantil usurpa dos pais essa função.

As mais influentes ONGs que atuam na área do consumismo infantil no país são o Instituto Brasileiro de Defesa do Consumidor (Idec) e o Instituto Alana, cujo projeto "Criança e consumo" visa a pressionar as autoridades públicas, mormente os órgãos de proteção da criança e do adolescente, os órgãos de defesa do consumidor, e provocar o controle judicial da atividade publicitária. ${ }^{9}$ As duas entidades já encaminharam inúmeras denúncias aos Ministérios Públicos (estaduais e federal) e aos Procons,

aviso de sua classificação, antes de sua transmissão, apresentação ou exibição”.

${ }^{9}$ Idec. Idec e Projeto Criança e Consumo do Instituto Alana realizam mesa redonda. Disponível em: <http://www.idec.org.br>. Acesso em: 25 set. 2015; Alana. Idec e Alana cobram medidas efetivas sobre publicidade infantil de alimentos. Disponível em: $<\mathrm{http}$ ://www.alana.org.br>. Acesso em: 25 set. 2015. 
tendo proposto também ações civis públicas contra fornecedores de produtos e serviços que focavam suas propagandas no público infantojuvenil de forma abusiva ou clandestina.

O Instituto Alana atuou na função de amicus curiae numa ação julgada em março de 2016 pelo Superior Tribunal de Justiça, ${ }^{10}$ condenando uma grande empresa nacional do ramo de alimentos por publicidade voltada ao público infantil, caracterizada como venda casada. A ação civil pública dirigiu-se contra a campanha publicitária que oferecia relógios inspirados em personagens infantis, caso o consumidor adquirisse cinco pacotes de bolachas e pagasse mais R\$5,00. Para o ministro Herman Benjamin, trata-se de um "caso paradigmático" no STJ, que servirá de referência para as campanhas publicitárias da indústria alimentícia. No seu voto, ele alega que " $n \tilde{o}$ o se trata de paternalismo sufocante nem moralismo demais, é o contrário: significa reconhecer que a autoridade para decidir sobre a dieta dos filhos é dos pais” e que “nenhuma empresa comercial e nem mesmo outras que não tenham interesse comercial direto, têm o direito constitucional ou legal assegurado de tolher a autoridade e bom senso dos pais. Este acórdão recoloca a autoridade nos pais". ${ }^{11}$

\section{O PROJETO DE LEI N. 5.921/2001 E O SEU SUBSTITUTIVO, DE 2008}

Em julho de 2008 a Comissão de Defesa do Consumidor da Câmara dos Deputados aprovou o substitutivo do Projeto de Lei (PL) n. 5.921/2001, de autoria do deputado Luiz Carlos Hauly (PSDB-PR), que

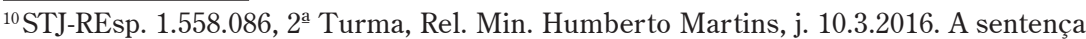
manteve a condenação proferida pelo Tribunal de Justiça do Estado de São Paulo (TJSP - 7ª Câmara de Direito Privado, Rel. Des. Ramon Mateo Jr., Registro: 2013.0000257478, j. 8.5.2013).

${ }^{11}$ Disponível em: <www.migalhas.com.br/Quentes/17,MI235576,101048->.
} 
propôs a reforma do CDC para proibir a publicidade infantil, propondo que o artigo 37 passasse a ter um $\S 2^{\circ} \mathrm{A}$, que proíbe “a publicidade destinada a promover a venda de produtos infantis, assim considerados aqueles destinados apenas à criança”.

A deputada Maria do Carmo Lara, no seu voto de relatoria da Comissão de Defesa do Consumidor sobre o PL 5.921/2001, de 2008, entendeu que a publicidade dirigida às crianças e adolescentes catalisa o "processo de querer e desejar coisas", justamente porque os jovens ainda não desenvolveram suficientemente uma "razão crítica”. Ainda que a publicidade seja uma parte do "jogo do consumo" e tenha um papel importante na economia, ela deve respeitar as regras deste jogo e levar em conta a capacidade dos seus participantes. A deputada enfatiza que crianças e adolescentes não possuem "a mesma capacidade de resistência mental e de compreensão da realidade que um adulto e, portanto, não estão em condições de enfrentar com igualdade de força a pressão exercida pela publicidade no que se refere à questão do consumo”. Vale frisar também que a deputada não acredita "que regras gerais, que apontam apenas princípios, sejam o suficiente para normatizar esta questão, pois é preciso determinar da forma mais exata e precisa possível o que é e o que não é permitido fazer em publicidade dirigida à criança e ao adolescente" (HAULY, 2009, p. 152 et seq.).

Em relação às regulamentações legais de outros países, especialmente as europeias e norte-americanas, faz sentido alegar que a criança brasileira deve ter uma proteção igual ou maior que as crianças desses países mais desenvolvidos, uma vez que o poder aquisitivo das famílias naqueles países é superior, o que acontece também em relação ao nível de educação formal e de informação disponível para as crianças que lá residem. Sem entrar nos detalhes destas legislações, pode-se afirmar que existe unanimidade quanto à necessidade de se restringir ou mesmo proibir publicidade infantojuvenil, tendo em vista a fragilidade e a vulnerabili- 
dade dos menores. As normas vão desde a imposição de uma publicidade clara, honesta e consciente até a proibição total; além disso, há proibição de uso de técnicas subliminares e da associação da publicidade com programas infantis, entre várias outras medidas (HAULY, 2009, p. 159 et seq.).

O Substitutivo do PL 5.921/01 (HAULY, 2009, p. 162 et seq.) especifica a vedação da publicidade infantojuvenil de cunho comercial (até 12 anos) e regulamenta as mensagens publicitárias para os adolescentes (entre 12 e 18 anos). O seu artigo $3^{\circ}, \S 1^{\underline{0}}$, apresenta um rol exemplificativo da publicidade ou comunicação mercadológica para crianças: a propaganda que se vale de atributos infantis, linguagem infantil e efeitos especiais com excesso de cores, trilhas sonoras de cunho infantil e cantadas por vozes de crianças, além de representação de crianças, pessoas ou mesmo celebridades com apelo ao público infantil; também inclui a publicidade em que há a utilização de personagens de desenhos animados, bonecos e outros semelhantes, bem como a distribuição de prêmios ou brindes colecionáveis com apelos infantis, promoções, competições ou jogos também no mesmo intento apelativo às crianças.

De modo idêntico, é vedada a comunicação comercial para todo público consumidor durante a programação infantil, assim como 15 minutos antes e depois dos programas infantis na televisão, rádio ou Internet. Além disso, proíbe-se a participação de crianças em campanhas publicitárias, exceto propagandas institucionais de natureza e interesse públicos, solidários e sociais.

No que respeita à publicidade focada nos adolescentes, a proposta aprovada na Comissão de Defesa do Consumidor não alterou a redação original baseada no Código de Autorregulamentação Publicitária e em 
normas internacionais de controle da publicidade infantojuvenil. ${ }^{12}$ Assim, o Projeto proíbe o merchandising, que ocorre quando determinada marca de produto aparece em programas de televisão (ex.: novelas) e constitui publicidade clandestina (subliminar). Foi determinada também a responsabilidade solidária (administrativa e civil) do fornecedor de produtos e serviços e das agências publicitárias e veículos de comunicação em que a mensagem foi transmitida. Em 2009, o Projeto seguiu para a Comissão de Desenvolvimento Econômico, Indústria e Comércio (CDEIC), na qual as discussões se ampliaram; ${ }^{13}$ a proposta aprovada na CDEIC pretende alterar o $\S 2^{\circ}$ do artigo 37 do $\mathrm{CDC}$, a fim de que o conceito de publicidade abusiva seja o disposto a seguir:

\begin{abstract}
Art. 37 (...)
$\S 2^{\circ} \mathrm{E}$ abusiva, dentre outras, a publicidade discriminatória de qualquer natureza, em qualquer meio, que incite a violência, explore o medo ou a superstição, aproveite-se da deficiência de julgamento e experiência da criança, que seja capaz de induzir a criança a desrespeitar os valores éticos e sociais da pessoa e da família, desrespeite valores ambientais,
\end{abstract}

${ }^{12}$ Em 1937, a Câmara de Comércio Internacional (CCI) editou o Código Internacional da Prática Publicitária, que já sofreu varias revisões. Ele traz diretrizes para os códigos nacionais de autorregulamentação e influencia as normas de autocontrole da publicidade editadas pelas entidades de controle desta atividade no mundo inteiro. Grande parte das regras nacionais sobre autocontrole da publicidade infantil foi inspirada nos dispositivos do Código. Ele ressalta que mensagens publicitárias não devem comprometer atitudes, comportamento social e estilo de vida das crianças, além de estabelecer que produtos não destinados às crianças não devem ser anunciados a elas, devendo a mensagem da publicidade infantil ser adequada à sua faixa etária. O Código enfatiza a prevenção de danos (mensagens publicitárias que incentivem comportamentos perigosos) e a proteção dos valores sociais, que procuram tutelar a criança contra os estímulos do consumismo e o uso de estratégias que agridem negativamente a família e sua convivência social; além disso, aborda a comunicação comercial por meios eletrônicos (cf. BRITTO, 2010).

${ }^{13}$ Os representantes da sociedade civil organizada (Instituto Alana, Idec e Conselho Federal de Psicologia) foram favoráveis à restrição à publicidade infantil; as instituições públicas presentes (Ministério da Justiça e Anvisa) defenderam a restrição da atividade publicitária. Já as entidades representantes da indústria de alimentos e de brinquedos, bem como as organizações representantes dos publicitários, foram contrárias à proposta, alegando a liberdade total da publicidade dirigida ao público infantil (Câmara dos Deputados, 2009). 
que estimule o consumo excessivo, ou que seja capaz de induzir o consumidor a se comportar de forma prejudicial ou perigosa à sua saúde ou segurança.

Essa proposta, entretanto, não pôs termo às discussões sobre publicidade infantojuvenil, pois permite interpretações variadas acerca do conceito de "abusividade". O atual texto do PL 5.921 traz poucas alterações do $\mathrm{CDC}$, uma vez que se vale de conceitos bastante indeterminados sobre a publicidade infantojuvenil, em vez de impor uma proibição expressa e contundente desse tipo de publicidade. No momento, o projeto aguarda o parecer do Relator da Comissão de Constituição e Justiça (CCJC).$^{14}$

\section{CONCLUSÃO}

$\mathrm{Na}$ contramão dos princípios constitucionais familiares dispostos na Constituição de 1988, anda o incremento de condutas desagregadoras no seio das famílias, ocasionado pelo consumismo alienador, cujos reflexos se fazem presentes nas relações sociais e familiares. A cultura consumista ajudou a erigir novos padrões, modos comportamentais, costumes e hábitos que influenciaram toda uma geração de jovens e adultos, na qual o consumo se estabeleceu como algo central na vida dos indivíduos. Destas relações de vivência emergiu a coisificação humana, uma vez que as pessoas que convivem no entorno de objetos terminam por gerar padrões relacionais semelhantes à forma como lidam com as coisas.

Dessa forma, a sociedade de consumo corroborou para o ambiente de instabilidade familiar, emocional e social, dirimindo a importância dos desejos coletivos de bem-estar e solidariedade nas relações familiares. Ao mesmo tempo, firmou-se uma crítica denunciativa da omissão do Estado

\footnotetext{
${ }^{14}$ Disponível em: <www.camara.gov.br/proposicoesWeb/fichadetramitacao? idProposicao $=43201>$. Acesso em: 27 set. 2015.
} 
e de seu descaso na fiscalização e no combate às anomias sociais que afrontam a família. A busca de um paradigma lastreado no princípio da dignidade da pessoa humana não pode prescindir do Direito, na forma de leis protetivas e incentivadoras do consumo responsável e consciente, ao lado de políticas educacionais do Estado voltadas a este objetivo. Neste sentido, são louváveis os Projetos de Lei que tramitam no Congresso Nacional com o fim de controlar melhor a propaganda comercial que tem por alvo as crianças e os adolescentes.

Por fim, resta constatar que o enfrentamento dos problemas advindos do consumismo infantil não depende tão somente do Estado e do Direito, mas principalmente de uma atitude positiva dos pais, que possuem a autoridade parental sobre seus filhos e têm a obrigação de cuidar e educá-los conforme valores dignos da pessoa humana.

\section{REFERÊNCIAS}

BAUDRILLARD, Jean. A sociedade do consumo. 2. ed. Lisboa: Edições 70, 2011. BAUMAN, Zygmunt. Amor líquido: sobre a fragilidade dos laços humanos. Trad. C. A. Medeiros. Rio de Janeiro: Zahar, 2004.

Vida para o consumo: a transformação das pessoas em mercadoria. Trad. C. A. Medeiros. Rio de Janeiro: Zahar, 2007.

BOURDIEU, Pierre. A distinção: crítica social do julgamento. São Paulo: Edusp, 2007.

BRITTO, Igor Rodrigues. Controle da publicidade infantil em Direito Comparado. Revista Jus Navigandi, Teresina, n. 2, 711, dez. 2010. Disponível em: $<$ https://jus.com.br/artigos/17961>. Acesso em: 27 set. 2015.

CÂMARA DOS DEPUTADOS. Comissão aprova mudanças em publicidade de produto infantil. Out. 2009. Disponível em: <www2.camara.gov.br/comissoes/ cdeic/comissao-aprova-mudancas-em-publicidade-de-produto/noticiasView $>$. Acesso em: 27 set. 2015. 
CAMPBELL, Colin; BARBOSA, Lívia (Org.). Cultura, consumo e identidade. Rio de Janeiro: FGV, 2013.

COSTA, Jurandir Freire. O ponto de vista do outro. Entrevistadora: Isabella Fraga. Ciência Hoje, vol. 8, p. 6-7, mar. 2012.

. O vestígio e a aura: corpo e consumismo na moral do espetáculo. Rio de Janeiro: Garamond, 2005.

COSTA, Sérgio. Amores fáceis: romantismo e consumo na modernidade tardia. Novos Estudos - Cebrap, São Paulo, n. 73, p. 111-124, nov. 2005.

DEBORD, Guy. A sociedade do espetáculo. Trad. E. Abreu. 12. reimpr. Rio de Janeiro: Contraponto, 2011.

FARIAS, Cristiano Chaves de; ROSENVALD, Nelson. Curso de Direito Civil: famílias. 7. ed. São Paulo: Atlas, 2015. Vol. 6.

FEATHERSTONE, Mike. Cultura de consumo e pós-modernismo. Trad. J. A. Simões. São Paulo: Studio Nobel, 1995.

FLORIANI, Dimas. Conhecimento, meio ambiente e globalização. Curitiba: Juruá, 2003.

FROMM, Erich. $A$ arte de amar. Trad. E. Brandão. São Paulo: Martins Fontes, 2006.

FUKS, Betty Bernardo. Freud \& a cultura. 2. ed. Rio de Janeiro: Jorge Zahar, 2007.

GAGLIANO, Pablo Stolze; PAMPLONA FILHO, Rodolfo. Novo curso de Direito Civil: Direito de família. São Paulo: Saraiva, 2011. Vol. VI.

GIDDENS, Anthony. Mundo em descontrole: o que a globalização está fazendo de nós. Trad.: M. Luisa X. de A. Borges. 5. ed. Rio de Janeiro: Record, 2006.

HAULY, Luís Carlos. Publicidade infantil: um polêmico projeto. Brasília: Senado Federal, 2009. Disponível em: <www.hauly.com.br/ps/42.pdf $>$. Acesso em: 11 dez. 2015.

KANT, Immanuel. Fundamentação da metafísica dos costumes. Trad. Paulo Quintela. Lisboa: Edições 70, 1986. 
LIPOVETSKY, Gilles. $O$ império do efêmero: a moda e seu destino nas sociedades modernas. Trad. M. Lúcia Machado. São Paulo: Companhia das Letras, 2009 .

LÔBO, Paulo Luis Netto. Direito Civil: famílias. São Paulo: Saraiva, 2008.

MORAIS, Maria Celina Bodin de. A nova família, de novo - estruturas e função das famílias contemporâneas. Pensar, Fortaleza, v. 18, n. 2, p. 587-628, maio/ ago. 2013.

NERY JÚNIOR, Nelson. O regime da publicidade enganosa no Código Brasileiro de Defesa do Consumidor. Revista de Direito do Consumidor, São Paulo: RT, n. 15, p. 210 et seq., jul./set. 1995.

PAES, Maria H. S. A década de 60: rebeldia, contestação e repressão política. São Paulo: Ática, 1995.

SANTOS, Milton. Por uma outra globalização. 6. ed. Rio de Janeiro: Record, 2001.

SARLET, Ingo Wolfgang. Dignidade da pessoa humana e direitos fundamentais na Constituição Federal de 1988. 8. ed. Porto Alegre: Livraria do Advogado, 2010 .

SARMENTO, Daniel. Direitos fundamentais e relações privadas. 2. ed. Rio de Janeiro: Lúmen Júris, 2008.

SCHOR, Juliet B. Nascidos para comprar: uma leitura essencial para orientarmos nossas crianças na era do consumismo. Trad. Eloisa Cabral. São Paulo: Gente, 2009.

SENNETT, Richard. A corrosão do caráter, o desaparecimento das virtudes com o novo capitalismo. Trad. M. Santarrita. Rio de Janeiro: BestBolso, 2012. SLATER, Don. Cultura do consumo e modernidade. São Paulo: Nobel, 2001. SOUZA, Michel Aires de. A gênese da sociedade individualista e consumista. 2012. Disponível em: <https://filosofonet.wordpress.com/2012/06/18/a-cultura-jovem-e-a-genese-da-sociedade-individualista-e-consumista/>. Acesso em: 13 abr. 2015. 
SOUZA, Michel Aires de. Experiência social e alienação. 2014. Disponível em: <https://filosofonet. wordpress.com/2014/02/27/experiencia-social-e-alienacao/>. Acesso em: 13 abr. 2015.

SUCUPIRA, Fernanda. Propaganda infantil deve ser regulamentada, dizem especialistas. Carta Maior, mar. 2006. Disponível em: <http://cartamaior.com. $\mathrm{br} /$ ?/Editoria/Direitos-Humanos/Propaganda-infantil-deve-ser-regulamentada-dizem-especialistas-/5/9766>. Acesso em: 18 set. 2015.

TEPEDINO, Gustavo. A disciplina civil-constitucional das relações familiares. In: BARRETTO, Vicente de P. (Org.). A nova família: problemas e perspectivas. Rio de Janeiro: Renovar, 1997.

VENTURA, Rodrigo. Mudanças no perfil do consumo no Brasil: principais tendências nos próximos 20 anos. In: Análise e construção de cenários. Rio de Janeiro: Macroplan, 2010. Disponível em: <www.macroplan.com.br/documentos/ artigomacroplan2010817182941.pdf>. Acesso em: 31 ago. 2015.

WAUTIER, Anne M. Para uma sociologia da experiência. Uma leitura contemporânea: François Dubet. Sociologia, Porto Alegre, ano 5, n. 9, 2003. Disponível em: <www.scielo.br/pdf/soc/n9/n9a07>. Acesso em: 15 fev. 2015.

Recebido em: 16/3/2016

Revisões requeridas em: 29/5/2016

Aprovado em: 11/8/2016 